\title{
Large Cities in the Process of New Industrialization
}

\author{
Fatima Dakhaeva* \\ Chechen State University, 364024 Grozny, Russia
}

\begin{abstract}
In our country, the ongoing processes of new industrialization are acquiring their own specifics, largely associated with the qualitative heterogeneity of its economic space. Large cities are one of the strongholds of the new industrialization. The following work into the concepts "new industrialization", "city". Briefly outlined existing approaches of assessing the processes of new industrialization. The work, based on the analysis of available statistical information, gives a characteristic of the processes of new industrialization in large cities of the country. It is shown that the importance of industry for the economy of these territories remains. To assess the processes of new industrialization from a qualitative point of view, the integration of available statistical information is proposed for calculating indicators in the context of large cities.
\end{abstract}

\section{Introduction}

Industrialization (from the Latin industria - activity, hard work) is a highly productive and efficient production activity carried out on a regular industrial basis, using professional labor, special technical and organizational means, knowledge, skills and technologies that can significantly increase labor efficiency, save time and consumed resources. From an organizational and technological point of view, industrialization is achieved through specialization and cooperation of works and processes [1].

Modern industrialization is aimed at ensuring significant savings in the use of natural resources, at creating waste-free production facilities that minimize negative impact on the environment. New industrialization is the modern stage of industrialization. Previously, industrialization was commonly understood as "the process of creating large-scale industries leading to a sharp increase in the technical equipment of labor and an increase in its productivity." Now such a definition is largely outdated and very narrowed. The central part of the essence of the concept of industrialization is new, highly efficient technologies that can significantly increase the technical equipment of labor and its productivity. The growth of labor productivity should be associated with an increase in the quality of the results of this labor, an increase in its efficiency, understood in the broadest sense, including in the sense of the costs of the required resources, including the ecosphere [2].

* Corresponding author: dahaevaf@mail.ru 


\section{The Concept of "Industrial Technology"}

Industrial technologies are high-performance technologies that use the most advanced technical means and methods of work in various spheres of human activity. Possession of these technologies and technical means require a high level of professionalism, labor discipline and responsibility of all participants in the labor process. Industrial technologies understood in this way can be applied not only in industrial production, but also in all life support complexes, in the spheres of household and communal services, trade and public catering, in education and medicine [4].

With the stated understanding, industrialization is the natural, only possible and permissible direction of civilizational development. At the same time, after the stage of initial industrialization, the stages of new (second, third, etc.) industrialization, super-, hyperindustrialization, etc., should logically follow.

Industrialization is associated with specialization and cooperation, which increases labor productivity, and the opposite movement (de-industrialization, post-industrialization) is associated with self-sufficiency, which leads to archaization of human activity, i.e. to its decomposition and degradation [3]. Post-industrialism and de-industrialization should therefore be associated with a movement towards the degradation, decay and decay of civilization.

Industrialization, as the leading direction in the development of civilization, is the direction of development of production methods, considered not from the traditional political and economic position (according to the leading property relations), but from the organizational and technological position, when the organization and production technology, understood in a broad sense, is considered decisive. From this point of view, there is no reasonable alternative to the industrial direction of development with its characteristic deep specialization, close cooperation and integration of production [7].

The main problem of Russia is associated with the loss of the domestic industry, the displacement of its own industries, products and services by foreign ones. This leads to production-technological and economic dependence. There was a curtailment of production of the most important types of products for industrialization - microelectronic and radioelectronic devices, electric motors and electrical equipment, metal-working machines, mechanization and automation equipment.

The loss of the domestic production base threatens the country's economic and political security. Simultaneously with this, the degradation of domestic applied science and experimental design and design base took place. Hundreds of design and engineering and applied research and design organizations, which ensured the functioning and development of the domestic industry, were liquidated. The personnel potential of engineers, designers and designers has been largely lost [8]. The prestige of the engineering profession has fallen, the quality of training specialists in the scientific, technical and production profile has decreased. The laboratory, experimental-production and design-engineering base for performing experimental-design and design-technological work on the creation of new models of equipment and technologies has been lost [5].

In the sphere of mass engineering and technical consciousness, false ideas about the promising directions of the country's civilizational development and the leading development guidelines - postindustrialism, digital economy, information technology, services and entertainment, prevailed [9]. The imposed ideas about the main direction of development in the form of a mandatory transition to new technological paradigms is inconsistent with the natural direction of development of all interconnected existing and emerging new technological orders.

Trends in scientific and technological progress, caused by the atmosphere of the postindustrial world, actually slow down this progress, lead to unreasonable distortions and 
distortions. The ideology of post-industrialism cannot be accepted as a norm for Russian civilization.

\section{Characteristics of New Industrialization in Major and Major Cities}

It should be noted that the assessment of the development of the processes of new industrialization in cities is complicated by a number of difficulties associated, among other things, with the lack of the necessary statistical information. This applies primarily to indicators characterizing the innovative and technological development of the industry. Considering the role of cities in the processes of new industrialization, we came to the conclusion that most scientists rely on large cities. This is confirmed by numbers. Among 83 constituent entities of the Russian Federation (excluding the Republic of Crimea and the city of Sevastopol), 61 have large cities. Therefore, they are in a number of subjects of the Russian Federation that provide the main contribution to the volume of industrial production. The share of the industry of largest cities of the country in the Russian indicators of the volume of shipped goods of own production, works and services performed on their own is shown in Table 1 [9].

Table 1. Contribution of largest cities to Russian indicators of the volume of shipped goods of their own production, works and services performed on their own for $2010,2020, \%$

\begin{tabular}{|c|c|c|c|}
\hline Year & Mining & Manufacturing industries & $\begin{array}{c}\text { Production and distribution of } \\
\text { electricity, gas and water }\end{array}$ \\
\hline 2010 & 20,3 & 54,1 & 61,4 \\
\hline 2020 & 13,7 & 52,3 & 53,2 \\
\hline
\end{tabular}

Note that the real contribution of large cities to the corresponding Russian indicators is higher, since the calculations did not use data that are not published in order to ensure the confidentiality of the primary statistical data received from organizations, in accordance with Federal Law No. 282-FZ of November 29, 2007 "On official statistical accounting and the system of state statistics in the Russian Federation." At the same time, large cities concentrate on their territory $6.7 \%$ of the number of mining organizations operating in the country, $13.8 \%$ of manufacturing enterprises and $18.2 \%$ of organizations involved in the production and distribution of electricity, gas and water. Comparison of the number of enterprises operating in large cities with their contribution to Russian industrial production (see table) makes it possible to conclude that large cities are the points of attraction for the most successful and active companies that play a significant role in the economy region [6].

We can conclude that publicly available statistical data allow us to characterize the development of industry in the city from a quantitative point of view. The available information is insufficient to consider the qualitative parameters. Therefore, in order to consider the importance of largest cities in the processes of new industrialization, it is necessary to expand the list of statistical indicators, supplementing them with those that can be used to characterize the innovative and technological development of industry concentrated on their territory [5]. Otherwise, the importance of a number of cities may be underestimated or overestimated. As a consequence, it is possible that the distribution of resources between different territories of the country and enterprises is incorrect (not corresponding to the real state of affairs). Therefore, improving the information base is also important from a management point of view. 


\section{Approaches to Assessing the Processes of New Industrialization}

Before considering the development of new industrialization processes in cities, it is necessary to decide what approaches should be used. As a rule, researchers focus on the analysis of statistical data [9]. Then the question arises: what indicators are needed and can be used to characterize new industrialization? The first approach, which the overwhelming majority of researchers agree with, is to use indicators of the number of people employed in certain types of economic activity, the volume of shipped goods of own production, works and services performed on their own for certain types of economic activity and its dynamics, indices of industrial production, etc. But these indicators do not make it possible to take into account the qualitative characteristics of the industry. The second approach links the characteristics of new industrialization processes with the development of high-tech industries. In this case, you can use the following indicators that are currently publicly available on the website of the Federal State Statistics Service [8]:

- the share of high-tech and knowledge-intensive sectors of the economy in GDP;

- the share of high-tech and knowledge-intensive sectors of the economy in the GRP;

- production of high-tech industrial products.

The answer to the question of what should be attributed to high-tech industries can be found on the official website of the Federal State Statistics Service. "The criterion for classifying as high-tech industries is a high level of technological development, determined by the ratio of R\&D costs to gross value added" [11]. Rosstat has determined a closed list of economic activities that are included in high-tech, medium-tech, high-level industries.

The structure of high-tech activities in accordance with the current statistical methodology includes the production of pharmaceutical products; production of office equipment and computers; production of electronic components, equipment for radio, television and communications; production of medical devices; measuring instruments, control, management and testing; optical devices, photographic and film equipment, watches; production of aircraft, including spacecraft.

Medium-tech activities include chemical production, this also includes the production of pharmaceutical products; manufacture of machinery and equipment; production of electrical machines and electrical equipment; manufacture of cars, trailers and semi-trailers; ship building and repair; production of railway rolling stock (locomotives, tram motor cars and other rolling stock); manufacture of motorcycles and bicycles; production of other vehicles and equipment not included in other groups [10]. The second approach assumes that, when characterizing the technological level of the industry of the territory, one should also pay attention to the location of enterprises producing unique products that are competitive in the world market, to the presence of innovative industries, etc. Thus, the main approaches to characterizing the processes of new industrialization are based on assessing the role of industry (or its individual branches, usually high-tech) in the economy of the corresponding territory and their distribution over it.

\section{Conclusions}

Large cities, which are the territory of concentration of industrial giants and innovative and high-tech companies, are participants in the growing processes of new industrialization. Industry, despite the development of other sectors of the economy, continues to retain its importance. Industrial enterprises concentrated on the territory of large cities provide more than half of the Russian volume of shipped goods of their own production, works and services performed on their own in the types of activities "Manufacturing", "Production and distribution of electricity, gas and water." Attempts to assess the processes of industrial 
restructuring on a qualitatively new technological basis in cities are associated with a number of difficulties. One of them is the lack of the necessary statistical information in the public domain. The solution to the problem is seen in the integration of the available primary information to calculate additional indicators characterizing the innovative and technological development of industry in large cities of Russia.

\section{References}

1. V.M. Kulkov, Economics. Taxes. Pravo, 81 (2018)

2. Ya.P. Silin, E.G. Animitsa, N.V. Novikova, Facing the Challenges of the Third Wave of Industrialization: Country, Region, 14 (2019)

3. S.A. Sertyshny, High-tech industrialization of the Russian economy of the XXI century: pro et contra, New industrialization of Russia, Theoretical and management aspects: collective monograph, 30 (2020)

4. L.A. Velikhov, Basics of urban economy, General Doctrine of Urban Economy, 216 (2018)

5. N.P. Antsiferov, Ways to Study the City as a Social Organism: An Integrated Approach Experience, 151 (2020)

6. Urban Development Code of the Russian Federation: Feder. Law of May 7, 1998 No. 73-FZ

7. V.A. Novikov, Bulletin of KSU im. ON. Nekrasov, 179 (2019)

8. E. Primakov, Rossiyskaya Gazeta, 09.06.2012

9. O.A. Romanova, Schumpeterian Readings, 145 (2019)

10. E.B. Dvoryadkina, New industrialization: global, national, regional dimensions, 100 (2019) 